\title{
Predicting the Unpredictable - Harder than Expected
}

\author{
Anneli Eriksson, RN, MSc; ${ }^{1} \odot$ Martin Gerdin Wärnberg, MD, PhD; ${ }^{1} \odot$ Thorkild Tylleskär, Prof. MD; ${ }^{2}$ \\ Johan von Schreeb, $\mathrm{MD}, \mathrm{PhD}^{1}{ }_{\odot}$
}

1. Centre for Research on Health Care in Disasters, Health Systems and Policy Research Group, Department of Global Public Health Sciences, Karolinska Institutet, Stockholm, Sweden

2. Centre for International Health, University of Bergen, Bergen, Norway

Correspondence:

Anneli Eriksson, RN, MSc

Centre for Research on Health Care in Disasters Health Systems and Policy Research Group Department of Global Public Health Sciences Karolinska Institutet, Stockholm, Sweden E-mail: anneli.eriksson@ki.se

Conflicts of interest: none

Keywords: disasters; funding; needs; severity; vulnerability

\section{Abbreviations:}

7-eed: Severity and Needs Scoring Model

CRED: Centre for Research on the Epidemiology of

Disasters at the Université Catholique de Louvain

ECHO: European Civil Protection and

Humanitarian Aid Operations

EM-DAT: Emergency Events Database

GDAC: Global Disaster Alert and Coordination System

GNA: Global Humanitarian Needs Assessment HDI: Human Development Index

INFORM: Index for Risk Management

KI: Karolinska Institute

RMSE: root mean square error

UN: United Nations

Received: June 26, 2019

Revised: October 04, 2019

Accepted: October 13, 2019

\section{doi:10.1017/S1049023X20000217}

(C) World Association for Disaster and Emergency Medicine 2020. This is an Open Access article, distributed under the terms of the Creative Commons Attribution licence (http:// creativecommons.org/licenses/by/4.0/), which permits unrestricted re-use, distribution, and reproduction in any medium, provided the original work is properly cited.

\begin{abstract}
Introduction: An earthquake is a hazard that may cause urgent needs requiring international assistance. To ensure rapid funding for such needs-based humanitarian assistance, swift decisions are needed. However, data to guide needs-based funding decisions are often missing in the acute phase, causing delays. Instead, it may be feasible to use data building on existing indexes that capture hazard and vulnerability information to serve as a rapid tool to prioritize funding according to the scale of needs: needs-based funding. However, to date, it is not known to what extent the indicators in the indexes can predict the scale of disaster needs. The aim of this study was to identify predictors for the scale of disaster needs after earthquakes. Methodology: The predictive performance of vulnerability indicators and outcome indicators of four commonly used disaster risk and severity indexes were assessed, both individually and in different combinations, using linear regression. The number of people who reportedly died or who were affected was used as an outcome variable for the scale of needs, using data from the Emergency Events Database (EM-DAT) provided by the Centre for Research on the Epidemiology of Disasters at the Université Catholique de Louvain (CRED; Brussels, Belgium) from 2007 through 2016. Root mean square error (RMSE) was used as the performance measure.

Results: The assessed indicators did not predict the scale of needs. This attempt to create a multivariable model that included the indicators with the lowest RMSE did not result in any substantially improved performance.

Conclusion: None of the indicators, nor any combination of the indicators, used in the four assessed indexes were able to predict the scale of needs in the assessed earthquakes with any precision.
\end{abstract}

Eriksson A, Gerdin Wärnberg M, Tylleskär T, von Schreeb J. Predicting the unpredictable - harder than expected. Prehosp Disaster Med. 2020;35(2):174-183.

\section{Introduction}

A disaster arises as a consequence of an event that disrupts the functioning of a society, causing losses and needs that overwhelm local capacity and necessitate outside humanitarian assistance. ${ }^{1-6}$ Over the last decade, an average of 200 million people have been affected annually by disasters caused by natural hazards. ${ }^{7-9}$ Natural hazards that occur suddenly, such as earthquakes, can cause damage and a high number of casualties in a short time., ${ }^{2,9,10} \mathrm{Of}$ the 200 million people affected, eight million were affected by earthquakes alone, yet earthquakes caused one-half of all natural disaster deaths. ${ }^{7-9}$

Disasters arise as a combination of vulnerability and exposure to a hazardous event and as a consequence of the magnitude of the hazardous event., ${ }^{3,11} \mathrm{~A}$ society's vulnerability or susceptibility to a hazardous event is determined by factors such as the socioeconomic situation, where a resource-poor society in general tends to be more susceptible to the negative consequences of a hazard compared to a resource-rich society. $2,6,9,11$

Needs in a disaster are broadly defined by the number of people affected by the disaster, as well as the severity, which is ultimately manifested in excess mortality. ${ }^{1,12-14}$ The main governmental funders of humanitarian assistance have agreed that international funding should be based on disaster needs. ${ }^{4,5}$ For funding agencies that intend to fund disaster response "according to needs," cognizance of the nature of the needs must be combined with an estimation of the relative importance or scale as well as urgency of the needs. ${ }^{4,15,16}$ This approach should be comparable between disasters to allow for prioritization.,15,17,18 However, following earthquakes, information on needs and the scale of needs are scattered and incomplete, delaying a swift needs-based funding decision. ${ }^{19,20}$ 


\begin{tabular}{|c|c|}
\hline Hazard and Magnitude & $\begin{array}{l}\text { A phenomena or process that may lead to loss of lives and injuries or other damages. Hazards can be man-made } \\
\text { or natural with a slow or sudden onset in time. When referring to a specific hazard in time and place, the term } \\
\text { hazardous event is used. The magnitude of the hazardous event is one of the defining factors for a disaster. } \\
\text { Magnitude is defined by different factors for different disasters. For earthquakes, the Richter scale or the Moment } \\
\text { Magnitude scale is used, often in combination with the depth of the earthquake. In recent years, shake maps are } \\
\text { starting to be included. }{ }^{6} \text { In this study, the Moment Magnitude scale and the depth of the earthquake are used. }\end{array}$ \\
\hline Vulnerability & $\begin{array}{l}\text { The characteristics and circumstances of a community, system, or asset that make it susceptible to the } \\
\text { damaging effects of a hazard. }{ }^{3,6} \text { Vulnerability can be related to geophysical circumstances, individual } \\
\text { characteristics. }\end{array}$ \\
\hline Exposure & The people, property, systems, or other elements present in hazard zones that are subject to potential losses. ${ }^{6}$ \\
\hline Affected & $\begin{array}{l}\text { People who are directly or indirectly affected by a hazardous event. This study refers to affected as those who are } \\
\text { directly affected - people with injuries or health effects caused by the hazard, those who were displaced or } \\
\text { evacuated, or have suffered other direct damages to their lives or livelihood. }{ }^{6,32}\end{array}$ \\
\hline Severity & $\begin{array}{l}\text { The extent of the damage that a hazard has caused, }{ }^{3,15} \text { also referred to as the impact of a hazard. }{ }^{2} \text { The severity } \\
\text { of a disaster can ultimately be quantified as an increase in mortality. It is however rare to find precise and } \\
\text { unbiased estimates of mortality rates or excess death tolls in a timely manner. }{ }^{12,31} \text { From the perspective of a } \\
\text { responder or a funding agency, mortality in itself is of less interest, but important as a predicter for the severity of } \\
\text { the situation for people who are affected by a disaster - thus in need of assistance. In this sense, severity can be } \\
\text { defined as an outcome estimate as well as a risk estimate for future suffering and mortality., }{ }^{2,5}\end{array}$ \\
\hline Needs & $\begin{array}{l}\text { Needs is a concept with a large verity of definitions, from Maslow's pyramid, categorized human needs in a } \\
\text { hierarchy where physical needs for survival sets the base, followed by safety, social needs, esteem, and on the } \\
\text { top self-actualization. }{ }^{33} \text { In development and humanitarian aid, the concept of basic needs developed during the } \\
1970 \text { 's - mainly referring to basic services for a community and food, shelter, clothing for the individual, also } \\
\text { defined as standards for humanitarian assistance. To date, there is no common acceptance of how to define or } \\
\text { measure needs. }{ }^{15,16} \text { The concept of needs is also linked to future risks. }{ }^{15}\end{array}$ \\
\hline
\end{tabular}

Table 1. Definitions of Key Terminology

Nevertheless, decisions are needed. To guide swift decisions, prediction of the scale of needs is desirable. In the same manner as composite measures of different variables (indexes), which often are used to classify countries or societies in social science, ${ }^{21}$ an index that captures hazard and vulnerability could potentially support the objective and rapid prioritization of needs-based funding. ${ }^{22}$ While there has been a proliferation of indexes in this area in recent years, ${ }^{11}$ there is currently no commonly accepted disaster index model for the prediction of disaster needs. ${ }^{14,18,23-26}$ Many indexes require detailed information on the post-hazard situation, which makes them difficult to use for rapid needs-based funding decisions. ${ }^{27-29}$ In addition, indexes have rarely been validated against the scale of disaster needs after earthquakes and other sudden-onset events. ${ }^{11,30}$ Hence, there is a need for a composite index based on indicators that are available in the immediate aftermath of an earthquake and that have been shown to predict the scale of needs to enable swift needs-based funding decisions.

The aim of this study was therefore to identify and assess predictors of the scale of disaster needs after earthquakes.

This study's hypothesis stipulates an association among the indicators of vulnerability, exposure to, and magnitude of earthquakes and outcomes regarding the number of dead and affected people that, if taken into account, can enable the early prediction of needs and, in turn, swift and scale-adapted funding decisions.

Based on the Utstein logic for evaluating and researching disasters, ${ }^{3}$ the frame is also used in adapted forms by disaster indexes. ${ }^{3,18,24,25}$ Logic: information on the hazard event, the vulnerability of the society, and the number of people exposed should enable a prediction of disaster severity and the number of people affected, thereby predicting the size and urgency of needs.

\section{Methods}

Study Design

This analysis of secondary indicators and disasters requires data using linear regression models. The ability of a series of indicators to predict the scale of needs was assessed (Table $1^{31-33}$ ). In this study, "needs" refer to the relative scale of needs, which are the product of the severity of the disaster and the size of the affected population. Indicators were chosen from four commonly used disaster indexes. The indexes were selected because they assess risks, vulnerabilities, severity, or needs in relation to disasters on a global scale; have a published methods section; and are published or sponsored by a United Nation's (UN) branch as well as governmental humanitarian assistance funding agencies.

The selected indexes were: (1) the Global Humanitarian Needs Assessment (GNA) produced by the European Civil Protection and Humanitarian Aid Operations (ECHO; Brussels, Belgium) from 2004 through $2015 ;^{23}$ (2) the Index for Risk Management (INFORM), which replaced the GNA and is the result of a collaboration between the Inter-Agency Standing Committee (Geneva, Switzerland) Task Team for Preparedness and Resilience and $\mathrm{ECHO}$, with close to $20 \mathrm{UN}$ and governmental partners; ${ }^{24}$ (3) the UN's Global Disaster Alert and Coordination System (GDAC) earthquake alerts; ${ }^{26}$ and (4) a model developed by Karolinska Institute's (KI; Stockholm, Sweden) Severity and Needs Scoring Model (7-eed), which was initially intended for the severity scoring of complex emergencies. ${ }^{18}$

\section{Setting}

All earthquake events recorded in both the Centre for Research on the Epidemiology of Disasters' at the Universite Catholique de Louvain (CRED; Brussels, Belgium) Emergency Events Database (EM-DAT) and GDAC from 2007 through 2016 were selected for the analysis. The criteria for the CRED/EM-DAT inclusion in the database are one or more of the following: 10 or more people dead, 100 or more people affected, the declaration of a state of emergency, or a call for international assistance. ${ }^{34}$

\section{Variables}

Study Outcome-The root mean squared error (RMSE) with a $95 \%$ confidence interval (CI) of indicators, individually and in 


\begin{tabular}{|l|l|l|l|l|}
\hline Index & 7-eed KI & GNA & GDAC Earthquakes & INFORM \\
\hline Indicates & Severity and Need & Need & Expected Impact & Risk \\
\hline Index Logic & $\begin{array}{l}\text { Severity = Vulnerability* } \\
\text { Affected (outcome) Need } \\
\text { Severity* millions in need }\end{array}$ & $\begin{array}{l}\text { Need = Vulnerability } \\
\text { (index) + Crisis (index) }\end{array}$ & $\begin{array}{l}\text { Impact = Magnitude* } \\
\text { Exposure* Vulnerability }\end{array}$ & $\begin{array}{l}\text { Risk= Hazard and } \\
\text { exposure* Vulnerability* } \\
\text { Lack of coping capacity }\end{array}$ \\
\hline $\begin{array}{l}\text { Number (a) Single } \\
\text { Indicators; (b) Sub-Indexes }\end{array}$ & a) 4 & a) 6 & a) 4 & a) 24 \\
b) 0 & b) 4 & b) 1 & b) 6 \\
\hline
\end{tabular}

Table 2. Logic of the Four Assessed Indexes

Abbreviations: 7-eed, Severity and Needs Scoring Model; GDAC, Global Disaster Alert and Coordination System; GNA, Global Humanitarian Needs Assessment; INFORM, Index for Risk Management; KI, Karolinska Institute.
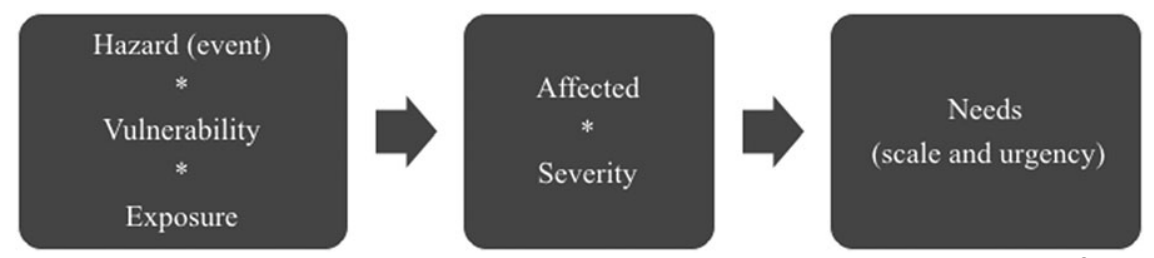

Eriksson () 2020 Prehospital and Disaster Medicine

Figure 1. Theoretical Framework.

different combinations, was used as the study outcome. The RMSE was chosen as it is commonly used to assess the predictability of models.

Model Outcomes - The outcome variables used were the number of people who died in the earthquake ("number of deaths") and the number of people affected by the earthquake ("number affected"). The two outcome variables were assumed to give information on needs (Figure 1). The data for the outcomes were extracted from the EM-DAT; the EM-DAT refers to the number of people who died in an earthquake as "deaths," which is explained as the "Number of people who lost their life because the event happened." 34 This outcome was selected to represent the severity of the situation instead of excess mortality, which is not available in the database. The number of people who lost their lives has been used as a disaster outcome in a previous validation study. ${ }^{30}$ The number affected refers to people injured in the earthquake, people left homeless after the earthquake, and people requiring immediate assistance during the period of emergency, as defined in the EM-DAT. ${ }^{34}$

Indexes - The four assessed indexes all included indicators for vulnerability, the magnitude of the hazardous event, and the number of people affected. Proxy indicators for coping capacity were used by one index. The number of indicators varied among the indexes.

Three of the four indexes included other composite indexes as indicators, which are hereafter called sub-indexes. Several of the indicators appeared both as single indicators and as indicators in the sub-indexes within the indexes. The GDAC uses both the GNA and INFORM vulnerability score as indicators. The assessed indexes use similar indicators to capture vulnerability; these are in most cases linked to the socioeconomic situation and the level of development, education, and health. For a detailed list of all index indicators, see Annex 1 (available online only).

Indicators - The choice of indicators to assess in this study is based on the theoretical framework, which is found in Figure 1. All indicators that were used in any of the indexes to indicate vulnerability, magnitude of the hazardous event, or exposure to the hazard were included in the study.

\section{Data Sources}

Data on the earthquakes and outcomes were obtained from both the CRED/EM-DAT and GDAC's archive. For detail, CRED at the Université Catholique de Louvain is a well-established research center whose database on natural disasters contains data from 1900 to the present. The database was established in 1988, and EM-DAT contains data on over 22,000 disasters. ${ }^{34}$ The GDAC was established in 2004 and includes more than one million earthquakes recorded from 1994 onwards. ${ }^{26}$

First, data on country, date, number of deaths, and total number affected were extracted from CRED/EM-DAT. Next, GDAC's alert data were matched with the list of earthquake events from CRED/EM-DAT. When event data in CRED/EM-DAT could not be matched with an alert in GDACs, they were removed. Finally, the earthquake magnitude, depth, and number of people living within 100 kilometers of the epicenter were extracted for the final list of earthquakes listed in both EM-DAT and GDAC. The number of people living within 100 kilometers of the epicenter was used as an estimate for the number of people exposed. To estimate the proportion of people who died ("proportion deaths") and the proportion of people who were affected ("proportion affected"), the number of people who died in the earthquake ("number deaths") and the number who were affected ("number affected") were divided by the number of people exposed.

The GDAC alert score for expected impact (Table 2) for each earthquake was extracted, and color codes were translated into numbers, with gray alerts becoming the lowest alert with a numerical value of zero and red alerts becoming the highest alert with a value of three.

The GNA scores per country were extracted for 2007 through 2013. For 2014 through 2016, data from 2013 were used. Scores varied from zero to three without decimal intervals.

The vulnerability scores from the INFORM index were extracted for 2013 through 2017. For preceding years, the scores from 2013 were used. The possible variation was from zero to 10 with decimal intervals. 


\begin{tabular}{|c|c|}
\hline Full Name or Explanation of Indicator: & Hereafter Presented As: \\
\hline Gross National Income per inhabitant on purchasing power parity & GNI \\
\hline Under-five mortality & Under-five mortality \\
\hline Chronic malnutrition rate in population under five years of age & Stunting \\
\hline Rate of underweight for age in population under five years of age & Underweight \\
\hline The Human Development Index & HDI \\
\hline The number of physicians per 100,000 population & Number physicians \\
\hline The percentage of $12-23$ months old immunized against measles & Measles immunization coverage \\
\hline Public and private expenditure on health & Health expenditure \\
\hline Public aid per capita & Aid/capita \\
\hline Net overseas development aid received as percentage of GNI & ODA \\
\hline The Gini index & The Gini index \\
\hline The Gender Inequality Index & The Gender Inequality Index \\
\hline $\begin{array}{l}\text { The number of uprooted: refugees, internally displaced, and } \\
\text { returnees in a given country }\end{array}$ & Uprooted \\
\hline The proportion of uprooted per country population & Proportion uprooted \\
\hline The number of people affected by natural disasters in the last three years & Number affected by natural disasters \\
\hline $\begin{array}{l}\text { The proportion of population affected by natural disasters in } \\
\text { the last three years }\end{array}$ & Proportion affected by natural disasters \\
\hline The prevalence of under-nourishment in the population & Undernourishment \\
\hline The average dietary energy supply adequacy & Diet supply \\
\hline The number of people within $100 \mathrm{~km}$ of the earthquake epicenter & Exposed \\
\hline
\end{tabular}

Table 3. Indicators and Sub-Indexes Assessed as Predictors for Severity and Scale of Needs Abbreviations: 7-eed, Severity and Needs Scoring Model; ECHO, European Civil Protection and Humanitarian Aid Operations; INFORM, Index for Risk Management.

Data for the vulnerability indicators used in the KI's 7-eed model were extracted from the World Bank (Washington, DC USA) online database for the respective years of the different events in the affected countries. When data for a specific year were missing, the closest data in time were used. The vulnerability was then scored according to the pre-established scoring system, ${ }^{18}$ with the possible range from two to six at intervals of 0.5 points, where six suggests the highest vulnerability.

Country data for vulnerability indicators were primarily sought from the World Bank online database. For a detailed list of sources, see Annex 2 (available online only).

\section{Study Size}

From 2007 through 2016, 255 earthquake events were identified in CRED/EM-DAT. Of these events, 28 could not be matched with GDAC alert data and were subsequently removed. In total, 227 events were included in the study.
Analyses and Statistical Methods

An initial mapping of the selected indexes was conducted that assessed: (1) the type of outcome (severity, risk, vulnerability, or needs); (2) the indicators used; (3) the index logic; and (4) the scoring system.

The variables were examined based on their ability to predict the outcomes, which were expressed as the number of people who died (number of deaths), the total number of people affected (number affected), and the proportion of deaths and people affected among the total number of people exposed to the hazard events.

Data collation was performed in a Microsoft Excel spreadsheet, version 16.11.11 (Microsoft Corporation; Redmond, Washington USA), and all analyses were conducted in $\mathrm{R}$ version 3.5.3 (2019-03-11) “Great Truth" (R Foundation for Statistical Computing; Vienna, Austria).

In an initial analysis, the score of each index was plotted against each of the outcome variables. Before the plotting, the index scores 


\begin{tabular}{|c|c|c|}
\hline Predictor & Number of Deaths & Number of Affected \\
\hline GNI & $316(111-1145)$ & $341539(144146-802152)$ \\
\hline Under-Five Mortality & $336(112-1144)$ & $342333(148409-798951)$ \\
\hline$H D I$ & $316(114-1139)$ & $338368(145251-796300)$ \\
\hline Number Physicians & $317(100-1144)$ & $341857(140441-807716)$ \\
\hline Measles Immunization Coverage & $332(111-1152)$ & $348807(150640-799038)$ \\
\hline Aid/Capita & $403(111-1146)$ & $340857(144234-796785)$ \\
\hline$O D A$ & $503(110-1145)$ & $340269(148115-797066)$ \\
\hline$T B$ & $327(106-1145)$ & $354452(142614-818819)$ \\
\hline Malaria Deaths & $347(101-1146)$ & $341980(136588-811584)$ \\
\hline Malaria Mortality & $311(100-1136)$ & $342430(136730-807120)$ \\
\hline Number Affected by Natural Disasters & $371(112-1133)$ & $354687(145949-791254)$ \\
\hline Proportion Affected by Natural Disasters & $357(113-1163)$ & $317867(151567-792467)$ \\
\hline Under Nourishment & $405(118-1095)$ & $367604(149877-779330)$ \\
\hline The 7-eed Vulnerability & $318(109-1143)$ & $342420(139162-805918)$ \\
\hline Magnitude-Earthquake & $411(119-1115)$ & $369619(137035-793953)$ \\
\hline Depth & $314(104-1126)$ & $343616(138488-811097)$ \\
\hline Exposed-Earthquake & $397(105-1186)$ & $390561(144193-794096)$ \\
\hline Stunting & $331(104-1140)$ & $342569(140495-811310)$ \\
\hline
\end{tabular}

Table 4. Cross Validated RMSE Across Predictors for Each Outcome (95\% CI)

Abbreviations: 7-eed, Severity and Needs Scoring Model; GNI, Gross National Income; HDI, Human Development Index; ODA, overseas development aid; RMSE, root mean square error; TB, Tuberculosis.

were first standardized, and outliers below the $10^{\text {th }}$ and above the $90^{\text {th }}$ percentiles were excluded, as these included extreme values.

The data were prepared to assess the predictive ability of individual indicators. First, indicators with more than $10 \%$ missing data were excluded from further analyses. Missing data in indicators with $10 \%$ or fewer missing data were imputed using median imputation (ie, missing data in an indicator were replaced using the median of observed data in the same indicator). Winsorizing was used to replace extreme outliers with the values observed at the $2.5^{\text {th }}$ and $97.5^{\text {th }}$ percentiles. Once extreme outlier values had been replaced, the data were split into a training and a validation set using a temporal split based on the date of an event. Two-thirds of the observations were assigned to the training set, and the remaining one-third were assigned to the validation set.

The predictive performance of the indicators was then estimated, first for each indicator individually and then in different combinations. The RMSE was used as the measure of predictive performance. To estimate the RMSE of an individual indicator, a linear regression model in the training set was built, with the outcome of interest as the dependent variable and the indicator as the only independent variable. This estimation was performed using a 10-fold cross validation, and the final RMSE is the median RMSE across the 10-fold in the training set.

The RMSE of different combinations of indicators was subsequently assessed. The first combination was the five indicators with the lowest RMSE. The second combination was the same as the first combination, but was forced to include the magnitude of the earthquakes if this indicator was not among the five with the lowest RMSE. The third combination included the vulnerability indicators included in the 7-eed model as well as magnitude, depth, and number exposed.

To estimate the RMSE of each combination, a linear regression model was built with the outcome of interest as the dependent variable and the indicators included in the combination as the independent variables. The model was built in the training set and then used to predict the outcomes of the observations in the validation set. The RMSE was estimated in the validation set. To estimate $95 \%$ confidence intervals (CI) around the RMSE point estimates, a bootstrap procedure was used, with 1,000 resamples drawn with replacement.

\section{Results}

The number of observations in the raw data was 227 earthquake events in 53 countries. The number of dead persons was recorded for 153 events and the number of affected persons for 222 events. In total, data for 26 variables were extracted (Table 3 ).

No obvious associations between the standardized index scores and number of deaths, number of affected, proportion of deaths, and proportion affected among exposed were visually observed in the initial analysis, where the index scores were plotted against the outcome (data not shown).

After excluding observations with missing values for event location, event date, or outcome, a total of 150 observations remained. Winsorizing was used to replace extreme outcome values with the values observed at the $2.5^{\text {th }}$ and $97.5^{\text {th }}$ percentiles. For number of deaths, four observations were replaced, and extreme 


\begin{tabular}{|c|c|c|c|c|c|c|}
\hline \multirow[b]{2}{*}{ Predictor } & \multicolumn{3}{|c|}{ Multivariable Model of No. of Deaths } & \multicolumn{3}{|c|}{ Multivariable Model of No. of Affected } \\
\hline & Coefficient & $95 \% \mathrm{Cl} \mathrm{lb}$ & $95 \% \mathrm{Cl} u b$ & Coefficient & $95 \% \mathrm{Cl} \mathrm{Ib}$ & $95 \% \mathrm{Cl} u b$ \\
\hline (Intercept) & 951 & -974 & 2,876 & 251285 & $-1,050,237$ & $1,552,807$ \\
\hline Uprooted & 0.000 & 0.000 & 0.000 & -0.07 & -0.43 & 0.29 \\
\hline The Gini Index & -6 & -38 & 26 & 7,364 & $-15,791$ & 30,519 \\
\hline Depth & -3 & -11 & 6 & & & \\
\hline $\begin{array}{l}\text { Proportion } \\
\text { Affected by } \\
\text { Natural Disasters }\end{array}$ & & & & 876,632 & $-438,204$ & $2,191,469$ \\
\hline $\begin{array}{l}\text { Proportion } \\
\text { Uprooted }\end{array}$ & & & & $-4,776,954$ & $-22,097,855$ & $12,543,945$ \\
\hline
\end{tabular}

Table 5. Multivariable Model with the Five Indicators Showing the Lowest RMSE Abbreviations: HDI, Human Development Index; RMSE, root mean square error.

\begin{tabular}{|c|c|c|c|c|c|c|}
\hline \multirow[b]{2}{*}{ Predictor } & \multicolumn{3}{|c|}{ Pre-Specified Multivariable Model of Number of Deaths } & \multicolumn{3}{|c|}{ Pre-Specified Multivariable Model of Number of Affected } \\
\hline & Coefficient & $95 \% \mathrm{Cl} \mathrm{lb}$ & $95 \% \mathrm{Cl} u b$ & Coefficient & $95 \% \mathrm{Cl} l \mathrm{lb}$ & $95 \% \mathrm{Cl} u b$ \\
\hline (Intercept) & $-1,158$ & $-3,384$ & 1,069 & $-377,131$ & $-1,922,376$ & $1,168,114$ \\
\hline Uprooted & 0.000 & 0.000 & 0.000 & -0.1 & -0.4 & 0.3 \\
\hline The Gini Index & -7 & -37 & 24 & 6,061 & $-17,021$ & 29,142 \\
\hline Depth & -8 & -16 & 0.8 & & & \\
\hline $\begin{array}{l}\text { Proportion } \\
\text { Affected by } \\
\text { Natural Disasters }\end{array}$ & & & & $1,132,911$ & $-218,625$ & $2,484,447$ \\
\hline $\begin{array}{l}\text { Proportion } \\
\text { Uprooted }\end{array}$ & & & & $-2,387,888$ & $-19,900,795$ & $15,125,018$ \\
\hline $\begin{array}{l}\text { Magnitude- } \\
\text { Earthquake }\end{array}$ & 330 & 132 & 528 & 102,896 & $-35,495$ & 241,286 \\
\hline
\end{tabular}

Table 6. Pre-Specified Multivariable Model with the Five Indicators Showing the Lowest RMSE and Magnitude Abbreviations: HDI, Human Development Index; RMSE, root mean square error.

outcome values were defined as those below one or above 4,580. For the number of affected persons, eight observations were replaced, and extreme outcome values were defined as those below 23 or above $2,822,990$. Out of the remaining 150 observations, a total of 100 observations were used to develop the models, and a total of 50 observations were used to validate the models. Table 4 shows the cross-validated RMSE associated with each predictor for each outcome. Indicators showing a significant value are presented in bold.

For the outcome variable "number of deaths," the five predictors with the lowest RMSE were malaria mortality, uprooted, the Gini index, depth, and Human Development Index (HDI). The RMSE (95\% CI) of the multivariable model for number of deaths was 632 (209-1,051).

For the outcome "number affected," the five predictors with the lowest RMSE were the Gini index, the proportion affected by natural disasters, the proportion uprooted, HDI, and the (number) uprooted. The RMSE (95\% CI) of the multivariable model for the number affected was $638,517(258,870-902,848)$

Table 5 shows the full model's parameter estimates with a $95 \%$ CI for number of deaths and number affected.
The RMSE (95\% CI) of the pre-specified multivariable model that, in addition to the five predictors with lowest RMSE, also included magnitude assessed against the outcome for number of deaths was 624 (286-996).

The RMSE (95\% CI) of the pre-specified multivariable model that, in addition to the five predictors with lowest RMSE, also included magnitude assessed against the outcome for the number affected was $602,070(236,477-853,497)$. Table 6 shows the full model's parameter estimates with a $95 \% \mathrm{CI}$. Indicators showing a significant value are presented in bold.

The RMSE (95\% CI) of the pre-specified 7-eed for the number of deaths was 712 (392-1,091).

The RMSE (95\% CI) of the pre-specified 7-eed model for the number affected was $595,932(252,828-840,877)$. Table 7 shows the full model's parameter estimates with a 95\% CI. Indicators showing a significant value are presented in bold.

In Figure 2 and Figure 3, the models with the lowest RMSE are compared with the actual outcome. For number of deaths, the prespecified multivariable model that, in addition to the five predictors with the lowest RMSE, also included magnitude (Figure 2) and number affected was the 7-eed model (Figure 3). 


\begin{tabular}{|c|c|c|c|c|c|c|}
\hline \multirow[b]{2}{*}{ Predictor } & \multicolumn{3}{|c|}{ Pre-Specified 7-eed Model of Number of Deaths } & \multicolumn{3}{|c|}{ Pre-Specified 7-eed Model of Number of Affected } \\
\hline & Coefficient & $95 \% \mathrm{Cl} \mathrm{lb}$ & $95 \% \mathrm{Cl} u b$ & Coefficient & $95 \% \mathrm{Cl} \mathrm{lb}$ & $95 \% \mathrm{Cl}$ ub \\
\hline (Intercept) & $-3,572$ & $-5,968$ & $-1,175$ & $-1,217,964$ & $-3,010,729$ & 574,801 \\
\hline $\begin{array}{l}\text { Under-Five } \\
\text { Mortality }\end{array}$ & 14 & -0.02 & 29 & 5,136 & $-5,698$ & 15,970 \\
\hline Adult Literacy Rate & 9 & -11 & 29 & 4,642 & $-10,306$ & 19,590 \\
\hline $\begin{array}{l}\text { Magnitude- } \\
\text { Earthquake }\end{array}$ & 436 & 236 & 635 & 174,322 & 24,996 & 323,648 \\
\hline Depth & -7 & -16 & 1 & $-2,072$ & $-8,335$ & 4,191 \\
\hline $\begin{array}{l}\text { Exposed- } \\
\text { Earthquake }\end{array}$ & 0.000 & 0.000 & 0.000 & 0.03 & 0.000 & 0.07 \\
\hline
\end{tabular}

Table 7. Pre-Specified 7-eed Model and Magnitude

Abbreviations: 7-eed, Severity and Needs Scoring Model; GNI, Gross National Income.

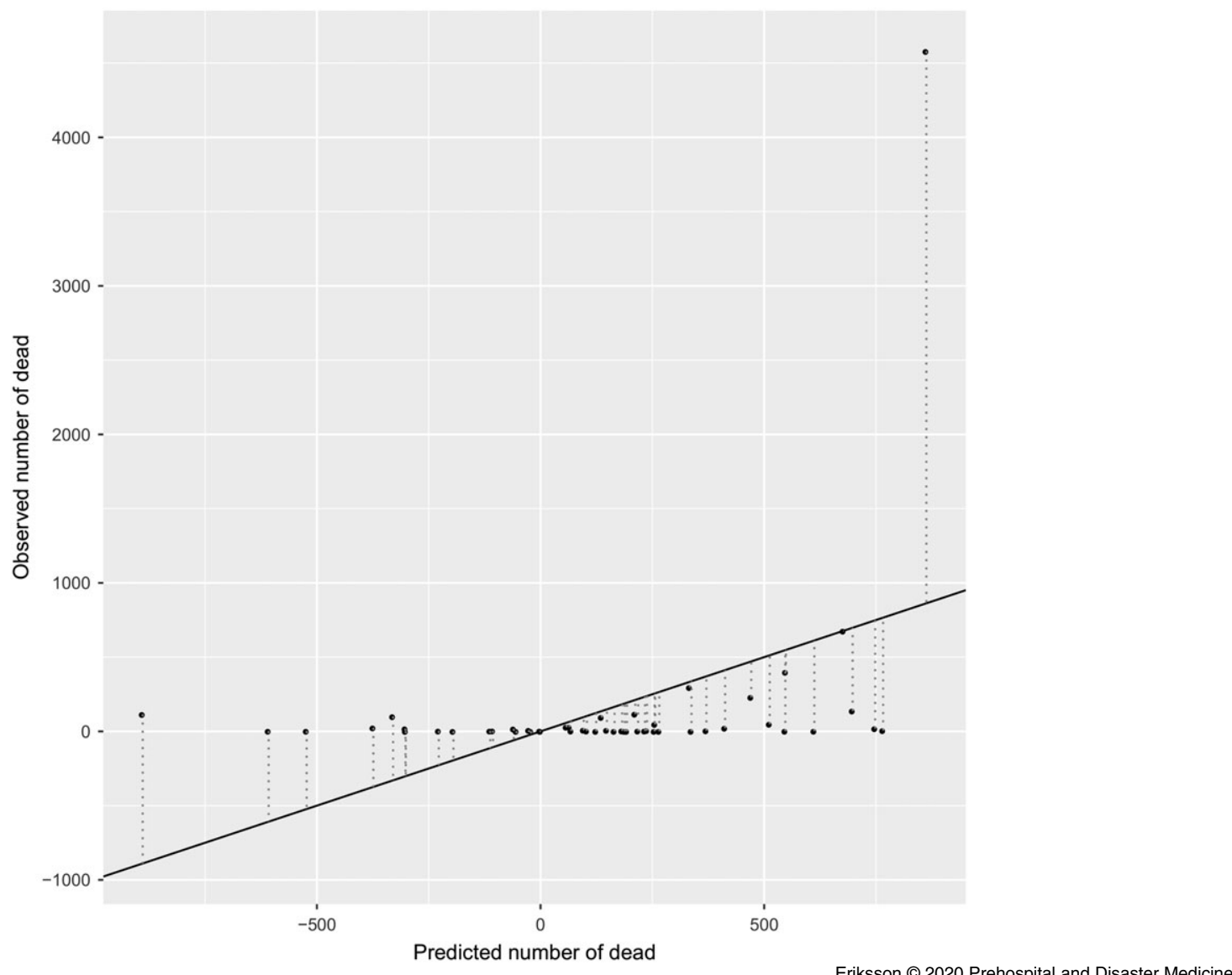

Figure 2. Plot Number of Deaths, Low RSME Plus Magnitude.

Abbreviation: RMSE, root mean square error.

Note that for Figure 2 and Figure 3, each black dot represents an event. The solid black line represents perfect agreement between observed and predicted outcomes. The dotted lines show the error between predicted and observed outcomes.

\section{Discussion}

The study was not able to identify any predictor that could capture the scale of needs after earthquakes. The hypothesis that estimates of vulnerability, the magnitude of a hazard, and the size of the population exposed can enable an early prediction of needs after earthquakes was rejected as no correlation was established between the outcome variables and the selected predictors. Neither the assessed indexes nor indicators correlated with the number of people who died in the earthquakes nor the number of people affected by the earthquakes.

The attempt to create a multivariable model that included the indicators with the lowest RMSE did not substantially improve 


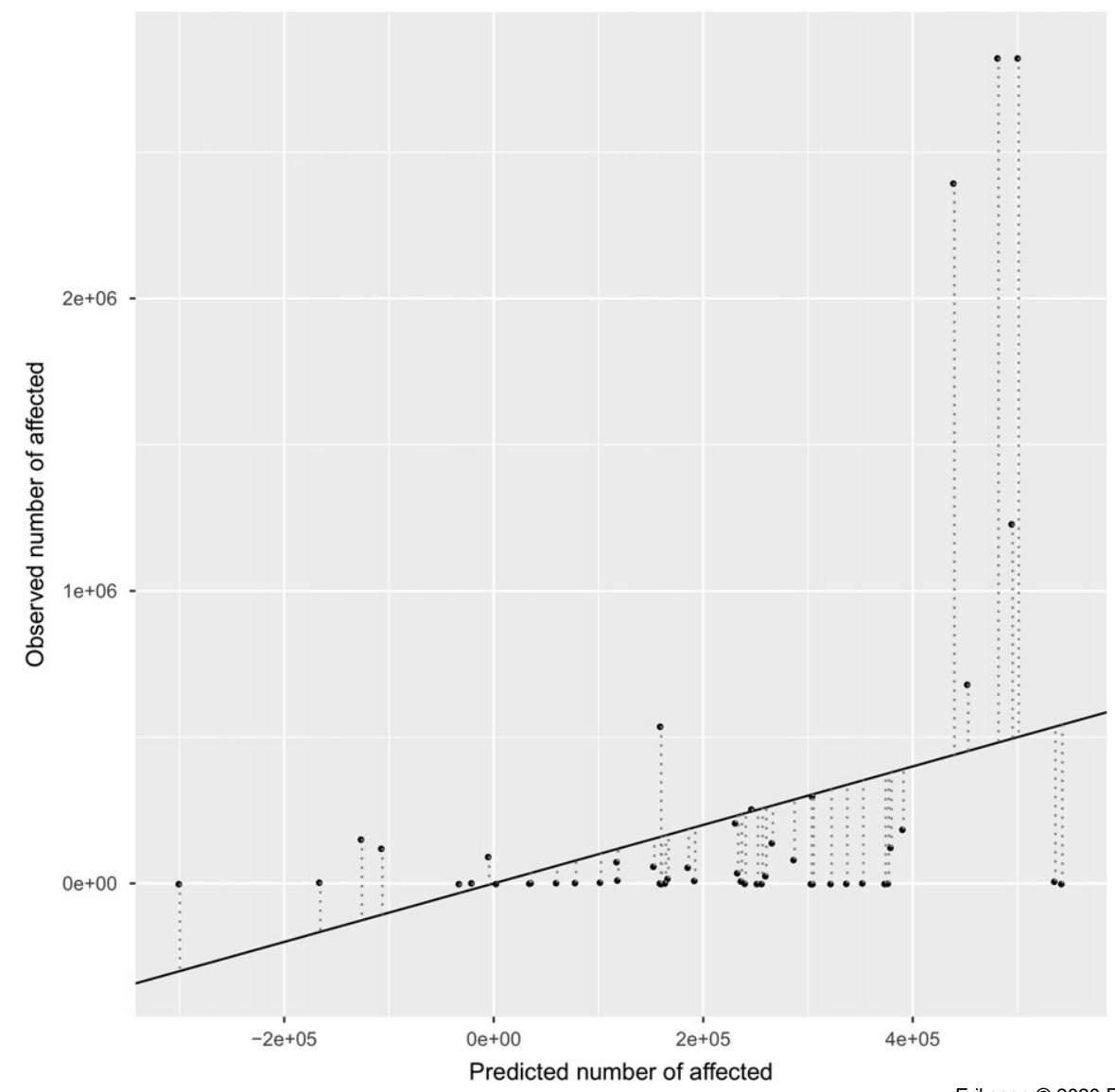

Figure 3. Plot Affected, 7-eed.

Eriksson () 2020 Prehospital and Disaster Medicine

Abbreviation: 7-eed, Severity and Needs Scoring Model.

the performance. The lowest RMSE attained in any of the combinations was 624 for number of deaths, with a confidence interval of 286-996. When the 7-eed indicators were combined with magnitude and exposure, the lowest RMSE reached was 712 for number of deaths, but the confidence interval was wide: $392-1,091$. For number affected, the RMSE remained above or close to 600,000 in all attempts, with a confidence interval with a range of over 600,000 , which makes the models incapable of predicting with precision or able to even broadly indicate an outcome.

While the authors of the study have found a correlation between the 7-eed model and excess mortality in protracted complex emergencies, ${ }^{14}$ this correlation did not apply to the studied earthquakes. The results of a similar study, a validation of indexes for vulnerability or resilience by Bakkensen, et al, also showed a limited or no correlation between number of deaths after sudden-onset natural disasters, ${ }^{30}$ which points to the uncertainty related to vulnerability indexes and the prediction of scale of needs in these types of disasters.

It is essential to raise critical questions following a study with negative results: Was the hypothesis wrong? Does the study use the right outcome to estimate the scale of needs? Was the study design or the data quality inadequate? Are the results correct? In disaster situations, outcome data may remain uncertain, and there may be inaccuracies in the data related to the number of people who die, ${ }^{35}$ or are affected by a hazard. For instance, Rivera and Rolke suggest that the excess mortality after Hurricane Maria in
Puerto Rica (2017) was significantly under-estimated. ${ }^{31}$ The term "affected" has several definitions. It can be defined in broad terms, including short- and long-term, directly and indirectly, and physically and psychologically affected. ${ }^{6}$ The numbers of people reported to be affected can therefore have large variations in the same disaster, depending on the definition.

The vulnerability indicators used in the indexes and models are based on country data. Variations in vulnerability within a country or between different groups within a country are not taken into account. These factors may cause a bias in the predicting variables. What are the (other) factors that should be taken into account to enable an early prediction of the scale of needs and needs-based funding for a response? There may be better predictors in the field of geophysical science and engineering that have not been included in this study. To better understand how needs can be predicted after earthquakes, more intradisciplinary research seems indispensable.

The choice of outcome variables may be misleading. Excess mortality, which is suggested as an ultimate measure of severity, will, in protracted disasters such as a conflict or drought, provide information about the on-going situation and the potential deterioration in terms of lack of services and livelihood. The assumption that the number of people who die in an earthquake is a proxy for severity does not take into account the possible excess mortality in the aftermath of an earthquake related to indirect causes, such as disrupted health services and food and water shortages. One can 
assume that a high socioeconomic vulnerability in a society will entail a limited capacity to respond to any needs, and as a consequence, a raise in excess mortality. Information on excess mortality was, however, not available.

The hypothesis assumes that severity and the number of people who are affected together will provide information on the scale of needs. The study stops short of assessing this link.

While a composite index that includes outcome variables, such as 7-eed, can be used to estimate the severity and scale of needs in complex emergencies, ${ }^{14}$ the findings of this study are significant as they illustrate that available indexes cannot be used to predict the scale of needs. The results should inspire further studies to guide needs-based funding decisions given the challenging context. One may assume that such decisions should be made with support from a variety of rapidly available data, as well as an understanding of the context in which a disaster occurs, in combination with information from responders and other sources present during the disaster. Uncertainty cannot be avoided and must be balanced with timing. Nevertheless, improved indexes are needed to ensure that the people who are most in-need receive humanitarian assistance after earthquakes. Swift decisions on humanitarian funding, in the absence of a prediction index, must balance uncertainty against urgency.

\section{Limitations}

The relatively low number of earthquake events limits the validity of the outcome. The definition of outcome variables may differ. The study builds on the definition used by CRED/EM-DAT for total number affected: injured, people who are left homeless, and those in-need of immediate assistance. However, as different definitions may be used by the actors who report on those affected, there could be some bias in the numbers. The disaster data in EM-DAT were not triangulated with that of other sources. The number of people who died in an earthquake stops short of informing on the overall excess mortality in the aftermath of an earthquake. This aspect has not been included in the study as data on overall excess mortality were not available. Initially, data on the number of people injured in the earthquakes were collected as an additional outcome variable, but the information was only available for one out of five of the events, and further outcome analysis was therefore discarded.

\section{Conclusion}

None of the indicators, nor any combination of the indicators, used in the four assessed indexes were able to predict the scale of needs in the assessed earthquakes with any precision.

\section{Supplementary Material}

To view supplementary material for this article, please visit https:// doi.org/10.1017/S1049023X20000217

\section{References}

1. Perry RW. Defining Disaster: An Evolving Concept. Handbook of Disaster Research. Berlin, Germany: Springer; 2018:3-22.

2. Keim M. Defining disaster-related health risks: a primer for prevention. Prehosp Disaster Med. 2018;33(3):308-316.

3. Sundnes KO, Birnbaum ML. Health disaster management: guidelines for evaluation and research in the Utstein style. Prehosp Disaster Med. 2003;17 (Supplement 3).

4. The Good Humanitarian Donorship Initiative (GHD). The Good Humanitarian Donorship Principles. 2003. http://www.goodhumanitariandonorship.org/gns/ principles-good-practice-ghd/overview.aspx. Accessed April 25, 2019.

5. United Nations Secretary General (UNSG). One humanity- shared responsibility. Report of the United Nations Secretary General for the World Humanitarian Summit, 2016. http://sgreport.worldhumanitariansummit.org. Accessed April 25, 2019.

6. United Nations Office for Disaster Risk Reduction (UNDDR formally UNISDR). Terminology. 2009 UNISDR terminology on disaster risk reduction. http://unisdr. org. Accessed April 25, 2019.

7. Centre for Research on the Epidemiology of Disasters (CRED). CRED Natural Disasters 2017. https://cred.be/sites/default/files/adsr_2017.pdf. Centre for Research on the Epidemiology of Disasters (CRED) Institute Health and Society, Université Catholique de Louvain. Accessed April 25, 2019.

8. United Nations Office for Coordination of Humanitarian Assistance (UNOCHA). World humanitarian data and trends 2018. https://www.unocha.org/sites/unocha/ files/WHDT2018_web_final_spread.pdf. Accessed April 25, 2019.

9. Wallemacq P, Below R, McLean D. UNISDR and CRED Report: Economic Losses, Poverty \& Disasters (1998-2017). Brussels, Belgium: CRED; 2018.

10. Ward PS, Shively GE. Disaster risk, social vulnerability, and economic development. Disasters. 2017;41(2):324-351.

11. Beccari B. A comparative analysis of disaster risk, vulnerability, and resilience composite indicators. PLoS Curr. 2016;8.

12. Checchi F, Roberts L. Documenting mortality in crises: what keeps us from doing better? PLoS Med. 2008;5(7):e146.

13. Salama $P$, Spiegel $P$, Talley L, Waldman R. Lessons learned from complex emergencies over past decade. The Lancet. 2004;364(9447):1801-1813.

14. Eriksson A, Gerdin M, Garfield R, Tylleskar T, von Schreeb J. How bad is it? Usefulness of the "7eed Model" for scoring severity and level of need in complex emergencies. PLOS Curr Disasters. 2016;8.

15. Darcy J, Hoffman C. According to need? Needs assessment and decision-making in the humanitarian sector. $H P G-O d i .2003(15)$.

16. Sphere Association. Humanitarian Charter and Minimum Standards in Humanitarian Response. Geneva, Switzerland: The Sphere Project; 2018.

17. United Nations Office for Coordination of Humanitarian Assistance (UNOCHA), Inter Agency standing committee (IASC). The Grand Bargain - Agenda for Humanity. https://www.agendaforhumanity.org/initiatives/3861. Accessed April 25, 2019.

18. Eriksson A, Ohlsén YK, Garfield R, von Schreeb J. Who is worst off? Developing a severity-scoring model of complex emergency affected countries in order to ensure needs-based funding. PLOS Curr Disasters. 2015;7.

19. Stoddard A, Poole L, Glyn T, Willitts-King B. Efficiency and inefficiency in humanitarian financing. Humanitarian Outcomes. December 2017.

20. International Federation of Red Cross and Red Crescent Societies I. Leave no one behind. World Disaster Report 2018. https://www.redcross.org/about-us/newsand-events/news/red-cross-launches-world-disasters-report.html. Accessed April 25, 2019 .

21. Mazziotta M, Pareto A. Methods for constructing non-compensatory composite indices: a comparative study. Forum for Social Economics. 2016.

22. Olin E, von Schreeb J. Funding based on needs? A study on the use of needs assessment data by a major humanitarian health assistance donor in its decisions to allocate funds. PLoS Curr. 2014;6.

23. European Civil Protection and Humanitarian Aid Operations (ECHO). Global Vulnerability and Crisis Assessment (GNA). 2014. http://ec.europa.eu/echo/files/ policies/strategy/gna_fca_2013_2014_map.pdf. Accessed April 25, 2019.

24. Inter-Agency Standing Committee, European Commission, Joint Research Centre. INFORM, index for risk management. http://www.inform-index.org. Accessed April 25, 2019.

25. The Assessment Capacities Project (ACAPS). The global emergency overview (GEO). https://www.acaps.org/countries. Accessed April 25, 2019.

26. United Nations and European Commission. The Global Disaster Alert and Coordination System (GDACS). http://www.gdacs.org/alerts/. Accessed April 25, 2019.

27. Bayram JD, Kysia R, Kirsch TD. Disaster metrics: a proposed quantitative assessment tool in complex humanitarian emergencies-the Public Health Impact Severity Scale (PHISS). PLoS Curr. 2012;4.

28. Yew YY, Castro Delgado R, Heslop DJ, Arcos Gonzalez P. The Yew Disaster Severity Index: a new tool in disaster metrics. Prehosp Disaster Med. 2019;31(5):76-82.

29. Birkmann J. Risk and vulnerability indicators at different scales: applicability, usefulness, and policy implications. Environmental Hazards. 2007;7(1):20-31.

30. Bakkensen LA, Fox-Lent C, Read LK, Linkov I. Validating resilience and vulnerability indices in the context of natural disasters. Risk Analysis. 2017;37(5):982-1004.

31. Rivera R, Rolke W. Estimating the death toll of Hurricane Maria. Significance. 2018;15(1):8-9. 
32. Centre for Research on the Epidemiology of Disasters (CRED). Glossary for the international disaster database -EM-DAT 2018. http://www.emdat.be/glossary. Accessed April 25, 2019.

33. Maslow AH. A Theory of Human Motivation. Midwest Journal Press; 2016.
34. Centre for Research on the Epidemiology of Disasters (CRED). EM-DAT; The international disaster database. https://www.emdat.be/. Accessed December 25, 2018.

35. Guha-Sapir D, Checchi F. 2018 science and politics of disaster death tolls. BMJ. 2018;362:k4005. 